\title{
A new social conflict on globalisation-related issues in Germany? A longitudinal perspective
}

\author{
Céline Teney* $\quad$ Li Kathrin Kaja Rupieper ${ }^{\dagger}$
}

September 2022

\begin{abstract}
We draw on cleavage theory to assess the emergence of a social conflict on globalisation-related issues among the German population between 1989 and 2019. We argue that issue salience and opinion polarisation are key conditions for a successful and sustainable political mobilisation of citizens, and thus for the emergence of a social conflict. In line with globalisation cleavage theory, we hypothesise that issue salience as well as overall and between-group opinion polarisation on globalisation-related issues have increased over time. Our study considers four globalisation-related issues: "Immigration", "EU", "Economic liberalism" and "Environment". While the salience of "EU" and "Economic liberalism" remains low during the observed period, we find a recent increase in the salience of the issues of "Immigration" (since 2015) and "Environment" (since 2018). Furthermore, our results point to rather stable attitudes on globalisation-related issues among the German population: we do not find any consistent evidence of an increase in overall or between-group polarisation over time. In conclusion, the idea of an emerging conflict around globalisation-related issues among the German population finds very little empirical support.

Keywords: globalisation cleavage, opinion polarisation, issue salience, attitudes, German population, longitudinal analysis
\end{abstract}

\footnotetext{
*Freie Universität Berlin, celine.teney@fu-berlin.de

${ }^{\dagger}$ Leibniz University Hannover, rupieper@wipol.uni-hannover.de Acknowledgements: The authors would like to thank Emanuel Deutschmann, Swen Hutter, the participants of the KZfSS special issue authors workshop - in particular Kathrin Ackermann and the editors of the KZfSS special issues for their valuable comments on a previous version of this manuscript.
} 


\section{Introduction}

In the last decade, consolidated western democracies have been facing increasingly successful political mobilisation against globalisation. Globalisation refers to the widening, deepening and speeding up of worldwide interconnectedness in its economic, socio-cultural and political dimensions. The 2016 Brexit referendum, the 2016 Trump US presidential election, and the continuing electoral success of Marine Le Pen from the French Front National comprise the most prominent examples of such a successful mobilisation. Germany is no exception to this trend: the AfD with its anti-immigration and Eurosceptic programme seems to have managed a breakthrough within the German political party landscape. These examples illustrate the academic debate on the rise of a new social conflict around globalisation-related issues. The aim of this article is to investigate empirically the emergence of such a conflict on globalisation-related issues among the German population. To this end, we draw on cleavage theory and consider the positive function social conflicts can have for social integration (see also Deitelhoof, this issue, for a similar perspective). We use survey data covering the past three decades to assess the emergence of such a conflict among the German population. Our longitudinal perspective enables us to contextualise the current and lively public and academic debates on opinion polarisation and conflict around globalisation-related issues. Indeed, understanding the historical evolution of such a conflict can put into perspective the alarmist voices that have become louder in the current academic and public debates on the rise of a new globalisation cleavage.

Our contribution is threefold: first, we shed light on the role of such conflicts for social integration according to cleavage theory and derive hypotheses on the emergence of a conflict on globalisation-related issues at societal and group levels. Second, we provide a conceptualisation of conflict that enables a straightforward empirical assessment of conflict evolution. By mirroring the literature on the politicisation of public debate (e.g. Hutter et al., 2016), we argue that opinion polarisation and issue salience are the two necessary conditions for sustainable political mobilisation - and thus for conflict - among the population. Lastly, we investigate empirically the extent to which a conflict on globalisationrelated issues has emerged in Germany by analysing survey data covering the last three decades. To this end, we assess the evolution of issue salience and attitudinal polarisation among the German population since the 1990s in respect of four issues related to globalisation: economic liberalism, EU, environment and immigration. We selected these four issue domains as they represent different dimensions of the growing interconnectedness between nation states. Economic liberalism refers to the border crossing of goods. The European integration process is an example of border-crossing political authority. Immigration can be defined as the border crossing of people. Lastly, the environmental issue refers to the border crossing of pollutants, with climate change as the currently most prominent example of the global interconnectedness of environmental issues.

In a nutshell, our results point to a recent increase in the salience of "Immigration" (since 2015) and "Environment" (since 2018), so that by the end of 
2019, these issues belong to the most frequently identified problems mentioned by Germans. By contrast, the salience of "Economic liberalism" and "Europe" remained very low during the observed time period 1989-2019. Furthermore, our results point to rather stable attitudes on globalisation-related issues among the German population over time: we do not find any consistent evidence of an increase in overall and between-group polarisation in respect of our four globalisation-related issues. All in all, the idea of an emerging conflict around globalisation-related issues among the German population finds very little empirical support. Our contribution is structured as follows: first, we draw on cleavage theory to describe the emergence of a conflict on globalisation-related issues. We then conceptualise conflict and argue that its emergence has two necessary conditions: issue salience as well as opinion polarisation within the overall population and between groups. When presenting these key conditions of a conflict, we hypothesise that issue salience, and overall and between-group opinion polarisation have increased over time with respect to globalisation-related issues. Next, we present the data and methods used in our empirical analysis. This is followed by the presentation and interpretation of our results, and lastly, our conclusion.

\section{The role of social conflict for social integration}

The recent successful and sustainable political mobilisation against globalisation observed in various consolidated western democracies has been interpreted as the manifestation of a social conflict around globalisation-related issues. According to the landmark work of Kriesi et al. (2008), globalisation pressures lead to the polarisation of citizens into groups of winners and losers who support antagonistic positions on globalisation-related issues: globalisation's losers tend to endorse positions favouring more national closure, while winners tend to support positions favouring more transnational integration and denationalisation. Scholars have indeed repeatedly pointed to an attitudinal divide on international trade (Jungherr et al., 2018), EU integration (De Vries, 2018), immigration (e.g., Teney et al., 2014) or the fight against climate change (e.g., McCright et al., 2016) among citizens in Europe.

When pointing to the rise of a globalisation cleavage in Western Europe, Kriesi et al. (2008) use the theoretical framework provided by Lipset and Rokkan (1967) in their seminal work on cleavages. Despite their focus on party competition, Lipset and Rokkan (1967) also describe the structuration of the population and its political mobilisation on social conflicts - the demand side of the political system. Focusing on the demand side of cleavage theory can shed light on the function and implications of such structural conflicts for social integration. According to Lipset and Rokkan (1967), the process of nation state formation led to the crystallisation of new conflicts based on opposing interests between citizens living in peripheral communities and supporters of a centralised state, and between secularists and defenders of the Church. Furthermore, the industrial revolution drove the crystallisation of new interest conflicts between 
citizens living in rural communities and citizens living in urban communities as well as between workers and owners of the means of production or employers. The process of repeated conflicts with other groups solidified collective identities and in-group solidarity. These social conflicts were thus structuring the society. They became rooted in grassroots movements and hierarchical organisations such as churches or labour unions (Hooghe and Marks, 2018). National mass political parties emerged as a channel for the expression and mobilisation of protest. Political parties thus became the instrument of expression of protest movements and "help to crystallize and make explicit the conflicting interests, the latent strains and contrasts in the existing social structure" (Lipset and Rokkan, 1967, p. 5).

Lipset and Rokkan (1967) argue that these fundamental societal divisions lead to the emergence of sustainable sociocultural cleavages that structure party competition. Accordingly, external shocks such as the industrial revolution lead to the rise of new conflicts between social groups that become rooted and organisationally institutionalised. These institutionalised social conflicts -or sociocultural cleavages- constitute the way societies are structured in periods of relative stability. They themselves become a means of political stabilisation, by providing individuals with a constellation of pre-existing alternatives for their own social and political integration (Bartolini, 2000, p. 22). In periods of abrupt changes resulting from external shocks, new social conflicts emerge and coexist with the prior cleavages. They force political parties to adjust to the realignment of citizens along the new conflict lines. This adjustment can take the form of intense internal friction within existing parties or in challenging parties focusing on the new conflict lines that emerge alongside the established parties (Hooghe and Marks, 2018).

Globalisation pressures - in particular with the opening up of national borders to goods with international trade, to people with immigration and to a supranational authority with the EU - constitute such an external shock that the result is the rise of new conflict lines between social groups (Kriesi et al., 2008). According to cleavage theory, we are currently experiencing a period of abrupt change with increasing globalisation pressures (Hooghe and Marks, 2018). This period is characterised by the emergence of new lines of social conflicts around globalisation-related issues. This, in turn, adds a further form of sense of belonging and in-group solidarity to this multi-layered structure of collective identities. These new group boundaries are built on contrasting levels of human capital and cosmopolitan or national outlook (Bornschier et al., 2021). Political parties need to adjust to this realignment of citizens showing conflictual interests on globalisation-related issues. This period of abrupt change can also lead to the emergence of challenging parties seeking to mobilise citizens on these globalisation-related issues, such as the AFD in Germany or UKIP in the UK. Once the political system has adjusted to this new social conflict, we will accordingly face a period of relative stability within society, as political parties will provide a channel for the expression of conflicting interests on globalisation-related issues.

According to cleavage theory, a conflict on globalisation-related issues has 
an integrative function by providing citizens with collective identities, in-group solidarity and pre-existing political alternatives. Social integration manifested through political stability is thus closely intertwined with the rooting of social conflicts within society. Both cleavage theory and conflict theory (presented at length in the article by Deitelhoff, this issue) consider the rooting of social conflicts within society to be an essential element of social integration. A major difference between these theories is Parsons' structural-functional framework used by Lipset and Rokkan in their cleavage theory: they assume that political stability will be the outcome of the crystallisation of social conflicts and that cleavages, once arisen, are "frozen" within the society. By contrast, conflict theory (Coser, 1956; Dahrendorf, 1971; Simmel, 1992) aims to unpack the role of social conflicts in societal dynamics and changes. Accordingly, as long as conflict partners respect the common rules and norms of the social structure, conflict contributes to social integration as it requires interactions between actors and implies the building of groups (Bonacker, 2003, Chapter 1).

The recent theoretical developments of the cleavage literature surrounding the emergence of a globalisation cleavage (e.g., Hooghe \& Marks, 2018; Kriesi et al., 2008) provide us with a fruitful framework for developing a set of hypotheses on the emergence of a conflict on globalisation-related issues. Indeed, as globalisation pressures have increased continuously in the last decades (see for example the KOF globalisation index for Europe in Gygli et al., 2019), we can expect such a conflict to have emerged in Germany. At this stage we should mention a limitation of our empirical analysis, however: owing to data availability restrictions, we focus exclusively on the structural component of a cleavage. According to Bartolini and Mair (1990), a cleavage requires three key components. The structural component refers to a coherent and consistent opinion divide within the population on a set of related issues. The organisational component relates to organisations such as political parties or civil society movements that represent the conflicting interests of the population on this set of related issues. Lastly, the normative component is constituted of coherent ideologies and collective identities around the two poles of the socio-political divide. In this article, we restrict our empirical assessment of the rise of a new conflict on globalisation-related issues in Germany to the structural component, leaving aside collective identities, common ideologies and political organisations. Hence, we refer to "conflict" instead of "cleavage" throughout the paper.

\section{Conceptualisation of conflict}

\subsection{Salience and polarisation as conditions of conflict}

Two conditions must be met for a political mobilisation based on globalisationrelated issues among citizens to be sustainable, and thus, to be able to speak of a social conflict. First, we need to observe opinion polarisation on globalisationrelated issues. We understand opinion polarisation as a process in which citizens position themselves increasingly on the two polar edges of an attitudinal 
divide (Barber and McCarty, 2015, p. 24) ${ }^{1}$. This characterisation of polarisation as a process is essential for assessing the emergence of a social conflict resulting from increasing globalisation pressures, as suggested by the cleavage literature. Opinion polarisation does indeed result in a decrease in social and political stability, as it reduces the probability of group formation at the centre of the opinion distribution and increases the likelihood of the formation of groups with distinctive, irreconcilable policy preferences (DiMaggio et al., 1996, p. 603). Studies on public opinion on globalisation-related issues based on a single-wave data design have been burgeoning. However, using cross-sectional analyses to point to antagonist public opinion cannot provide us with information on a potential opinion shift. Furthermore, empirical studies assessing the trend in support of or opposition to a globalisation-related issue have long been established in the social sciences debate (e.g., Czymara \& Dochow, 2018; Kuhn et al., 2016). However, focusing on the evolution of one polar edge in an attitude divide cannot shed light on shifts in the overall opinion distribution. An adequate measurement of polarisation does indeed require us to consider the entire distribution of an attitudinal item - including both polar edges and the middle-range positions. Longitudinal analyses on the evolution of opinion polarisation on globalisation-related issues in Europe have been much sparser and point to mixed evidence. For instance, Jennings and Stoker (2016) highlight an increase in opinion polarisation on immigration and the EU in the last decades in the UK. By contrast, other scholars point either to a stable level of polarised opinion or to a depolarisation trend (Munzert and Bauer, 2013) or to ambivalent results varying along the attitudinal dimensions surveyed (De Vries et al., 2021).

The fact that a large portion of the population holds antagonistic positions on globalisation-related issues is a necessary but not a sufficient condition of a social conflict. Issue salience among the population constitutes the second condition of social conflict. Indeed, polarised public opinion on non-salient issues is unlikely to lead to a social conflict nor political mobilisation around these issues (Hetherington, 2009). Dennison and Geddes (2019) argue for instance that the recent and growing success of anti-immigrant right-wing populist parties in Europe is mostly due to an increase in the salience of the immigration issue among the European population during the last decade. Indeed, they show that the proportion of citizens holding anti-immigrant attitudes has remained stable over the last decade, while Europeans seem to have considered immigration as an increasingly important issue over the last decade.

There is meanwhile an established research tradition in assessing the salience of globalisation-related issues in national parliaments (Rauh, 2015), in the media (Hutter et al., 2016) or in civil society (Meunier and Czesana, 2019). However, our knowledge of the evolution of issue salience on globalisation-related topics among the population is much more limited. Indeed, we only know that the

\footnotetext{
${ }^{1}$ We focus our contribution on opinion polarisation, and refrain from discussing other types of polarisation that have been receiving much attention in the last years, such as affective polarisation (see Druckman \& Levendusky, 2019) or partisan polarisation (e.g., Barber \& McCarty, 2015).
} 
salience of immigration among the population has increased in Western Europe in the last decade (Claassen and McLaren, 2022; Dennison, 2019). We will therefore expand this strand of research by assessing the salience of four issue domains related to globalisation: economic liberalism, the European Union, immigration and environment. We follow the usual operationalisation of issue salience (Dennison, 2019) by using an open survey question on the most important problem faced by their country.

In sum, by considering opinion polarisation and issue salience as the two conditions of social conflict, we can derive two hypotheses for assessing the emergence of a conflict on globalisation-related issues in Germany:

H1: The salience of the issues of economic liberalism, the European Union, immigration and environment has increased over time among the population in Germany.

$\mathrm{H} 2$ : Opinion polarisation on economic liberalism, the European Union, immigration and environment has increased over time in Germany

\subsection{Group-level opinion polarisation}

So far, we have conceptualised conflict at the societal level by operationalising issue salience and opinion polarisation within the entire population. However, and as discussed in the introductory paper of this special issue, social integration -and in our case social conflict- can be measured not only at societal or individual levels, but also at the group level. Groups sharing particular sociodemographic characteristics might hold antagonist opinions on a set of issues. If such opinion divide along socio-demographic characteristics is consistent for a set of issues related to the same overarching conflict, this would provide evidence for polarised opinion at the group level. Such group-level opinion polarisation, in turn, relates to the structural component of a cleavage, as described by Bartolini and Mair (1990): the fact that socio-demographic characteristics align with antagonistic opinions on a common set of issues implies that these sociodemographic characteristics structure the population on this conflict. According to our longitudinal perspective on conflict, we would be able to speak of grouplevel polarisation on globalisation-related issues (1) if we observed systematic socio-demographic differences in opinion on globalisation-related issues and (2) if these differences increased over time, as globalisation pressures have grown in the last decades.

Drawing on the cleavage literature, education is said to be the main factor structuring this conflict around globalisation issues (Bornschier, 2018; Hooghe and Marks, 2018). Human capital provides citizens with the necessary specialized skills to live an economically secure life in a world of open markets and growing international trade (Teney, 2016). Besides education, further socio-demographic characteristics shown to be significantly associated with our globalisation-related issues are (Mau et al., 2020; Teney et al., 2014): gender, income, age, level of urbanisation of place of residence, and region of residence 
(old vs new federal states of Germany). Accordingly, we would find evidence of group-level opinion polarisation on globalisation related issues if the association of these socio-demographic characteristics with attitudinal items on economic liberalism, the European Union, immigration and the environment has increased over time in Germany. This leads us to formulate our last hypothesis:

H3: The association of gender, education, income, age, level of urbanisation of place of residence, and region of residence with opinions favouring economic liberalism, the European Union, immigration and environment have increased over time in Germany.

\section{Data and methods}

We use the Politbarometer Trend Data file (Forschungsgruppe Wahlen, Mannheim, 2022) for analysing the salience of globalisation-related issues among Germans. For assessing opinion polarisation at both societal and group levels, we use the cumulated German General Social Survey or ALLBUS data (GESIS - Leibniz Institute for the Social Sciences, 2021). In the following section, we describe these two datasets and our operationalisation of issue salience and opinion polarisation.

\subsection{The Politbarometer Trend Data}

The Politbarometer asks on a monthly basis to a cross-sectional random sample of German respondents the following open question: "In your opinion, what are the most important and the second most important problems faced by Germany nowadays? ". ${ }^{2}$ For our paper, we analyse the answers to this questions from May 1989 to December 2020. The average number of respondents to this question is 2.474 per month. Respondents provide an open answer to this question without having been presented with any predefined answer categories. Interviewers subsequently categorise respondents' answers using a predefined coding scheme. This coding scheme remains constant over time. New categories are introduced only when respondents refer to a societal problem that has not been categorised adequately by the current coding scheme. By now and based on all answers given until the end of 2020, this coding scheme encompasses 134 categories. We then recode these 134 categories into 15 issue domains following the coding scheme of Hutter and Kriesi (2019), as presented in Table 1. We consider four out of the fifteen categories to be globalisation-related: "Economic liberalism" regroups issues linked to national economic protectionism, global markets, deregulation, privatisation or reduction of the national deficit and taxes. The

\footnotetext{
${ }^{2}$ The formulation of this question is not an ideal measure of issue salience, as correctly pointed out by Wlezien (2005): respondents were asked about the most important problem, rather than the most important issue. Issue and problem are not perfect synonyms. Respondents might indeed perceive an issue as important, but not consider it a problem (for instance if they are satisfied with the way the government deals with the issue). This limitation in the analysed survey item should be borne in mind when interpreting our results on issue salience.
} 
Table 1: Aggregated issue domains of societal problem in the Politbarometer Trend Data and their average salience

\begin{tabular}{|lr|lr|}
\hline \multicolumn{2}{|c|}{ Globalisation-related issues } & \multicolumn{2}{|c|}{ Issues not related to globalisation } \\
\hline Immigration & $9,4 \%$ & Economic situation & $34,2 \%$ \\
Environment & $5,3 \%$ & Welfare (incl. health) & $9,7 \%$ \\
Economic Liberalism & $2,9 \%$ & Security \& international conflicts & $5,3 \%$ \\
Europe & $2,6 \%$ & Education & $4,3 \%$ \\
& & Other & $4,0 \%$ \\
& & Democratic Renewal & $3,6 \%$ \\
& & Reunification & $3,3 \%$ \\
& & Radicalism and Islamism & $1,8 \%$ \\
& & Cultural Liberalism & $1,1 \%$ \\
& & Politics general & $1,1 \%$ \\
& & Infrastructure & $0,8 \%$ \\
\hline
\end{tabular}

"Environment" category encompasses answers dealing with environment protection, environmental disasters, climate change or renewable and nuclear energy. The "Europe" category refers to the European Union integration process, EU enlargement, introduction of the Euro or the Euro crisis. Lastly, the "Immigration" category encompasses answers relating to asylum seekers, so-called late repatriates, refugees, foreigners, or double citizenship.

We then collapse the individual-level dataset, yielding wave-specific voting shares for these 15 issue domains. Since every interviewee had the chance to name two important problems, we calculate every domain's voting share as the total number of votes falling into that domain divided by the total number of respondents $\times 2$. The resulting share indicates the wave-specific percentage of respondents stating that a problem belonging to this domain is either the single or second most important in Germany. We use this share as a measure for the overall societal salience of an issue.

The data that we use in this part of our analysis comprise 371 waves spanning a period of 30 years from 1989 to 2020. Since April 1990, the Politbarometer sample also covers the population living in East Germany. Yet, for our analysis, we exclude all East German respondents until February 1999 because an appropriate weighting factor has existed only since March 1999: Until February 1999, our sample consists of the West German observations weighted by a factor (v78) that ensures demographic representability for West Germany. From March 1999 onwards, our sample consists of both West and East German observations weighted with a joint weighting factor (V81) that compensates for the oversampling of East Germans and ensures demographic representability for Germany as a whole. 


\subsection{The cumulated ALLBUS data}

We use the cumulated ALLBUS data that cover the period 1991-2018 for assessing opinion polarisation. We select items that are as close as possible to the issue domains used in the salience analysis. We recoded some of them in such a way that higher values always denote attitudes more in favour of globalisation. Moreover, we restrict our analysis to items asked more than once in order to be able to capture the process of polarisation. Table 2 presents a list of the selected items. For the EU-issue, we use an item on trust in the European Commission and an item on European identification. Unfortunately, better measurements of attitudes towards the EU or EU integration are not available in the cumulated ALLBUS trend survey data. We include both the West German and East German observations in our sample, weighted by wghtptew, a weight that ensures demographic representability and accounts for the oversampling of East Germans.

We analyse opinion polarisation in three parts: First, we depict the evolution of the opinion distribution over time using bar charts. In order to facilitate the readability of these bar charts, we summarise all answer categories into three categories; two polar edges and a broad middle category containing all nonextreme answer categories (see Table 2 for more details).

Second, as a measure of polarisation, we calculate the agreement index proposed by van der Eijk (2001) for each item and data wave. This index can be calculated for ordinal-scaled items and refers to the proportion of respondents in contiguous answer categories. Applied to the example of a 5-point Likert scale, high agreement implies that a majority of cases are found in contiguous answer categories, for example the first and second ones. High disagreement by contrast implies that observations fall into non-contiguous answer categories, for instance $30 \%$ in the first answer category, $30 \%$ in the third answer category and $40 \%$ in the fifth answer category. Appendix B provides a more detailed description of its computation. The agreement index ranges from -1 to 1 . A value of -1 denotes complete disagreement as given by a bimodal distribution where $50 \%$ of all respondents fall into the first and the other $50 \%$ into the last answer category. A value of 1 refers to complete agreement, where all observations are to be found in a single category (perfect unimodality). An index value of 0 refers to a uniform distribution, where each answer category realises equally frequent. If the agreement index for any globalisation item falls over time, this constitutes another piece of evidence on polarisation and an emerging social conflict around globalisation. To complement the van der Eijk's agreement index as polarisation indicators, we provide the variance, kurtosis and skewness of these items in the appendix (Table A.1-A.3 in the appendix).

Third, we analyse group-specific opinion differences on globalisation by running simple linear regressions. In separate regression models, we regress our six attitudinal items on a list of socio-demographic characteristics, survey year dummies and their interaction terms. We consider the following socio-demographic characteristics: gender, age (categorised as 18-39 years, 40-59 years, and 60+ years old), education (low, middle, high), log personal net income per month, 
Table 2: Description of the selected ALLBUS items on globalisation-related issues

\begin{tabular}{|c|c|c|c|c|}
\hline $\begin{array}{l}\text { Related issue } \\
\text { domain in } \\
\text { Politbarometer }\end{array}$ & $\begin{array}{l}\text { ALLBUS } \\
\text { item }\end{array}$ & Label & $\begin{array}{l}\text { Number of } \\
\text { answer } \\
\text { categories }\end{array}$ & $\begin{array}{l}\text { Original } \\
\text { name in } \\
\text { ALLBUS }\end{array}$ \\
\hline $\mathrm{EU}$ & eu_trust & $\begin{array}{l}\text { How much do you trust } \\
\text { the European Commission? }\end{array}$ & $7^{*}$ & pt19 \\
\hline \multirow{3}{*}{ Immigration } & eu_id & $\begin{array}{l}\text { How strongly do you } \\
\text { identify with the European } \\
\text { community and its population? }\end{array}$ & $4^{+}$ & pn17 \\
\hline & mig_cult & $\begin{array}{l}\text { The foreigners who live in } \\
\text { Germany enrich the cultural } \\
\text { life of Germany. }\end{array}$ & $7^{*}$ & mp03 \\
\hline & mig_job & $\begin{array}{l}\text { The foreigners who live in } \\
\text { Germany take jobs away } \\
\text { from Germans. }\end{array}$ & $7^{*}$ & mp06 \\
\hline $\begin{array}{l}\text { Economic } \\
\text { liberalism }\end{array}$ & econlib & $\begin{array}{l}\text { Opening up global markets } \\
\text { even more will be to } \\
\text { everyone's benefit. }\end{array}$ & $5^{\circ}$ & pa18 \\
\hline Environment & envir & $\begin{array}{l}\text { Stronger measures should } \\
\text { be taken to protect the } \\
\text { environment. }\end{array}$ & $5^{\circ}$ & pa11 \\
\hline
\end{tabular}

Note: ${ }^{*}$ For the bar charts in Figure 2, we aggregate the answer categories 1-2 and 6-7 as the two polar edges. + Here, we recoded answer categories 2-3 as middle category. Categories 1 and 4 constitute the polar edges in the corresponding bar chart in Figure 2. ${ }^{\circ}$ The bar charts of these items presented in Figure 2 show answer categories 1 and 5 as polar edges.

region (East and West Germany), and level of urbanisation of the place of residence ( $<5.000$ inhabitants, $5.000-50.000$ inhabitants, $>50.000$ inhabitants). The interaction terms of these socio-demographic variables with the survey year dummies allow us to investigate our third hypothesis on an increase in grouplevel opinion polarisation. In case of missing information regarding the relevant variables, observations were deleted listwise. Table A.4 in the appendix presents the corresponding descriptive statistics.

\section{$5 \quad$ Results}

We first present the results derived from the Politbarometer data regarding the evolution of salience of globalisation-related issues. Then, we discuss the results on opinion polarisation derived from the ALLBUS data. 


\section{$5.1 \quad$ Issue Salience}

Figure 1 presents our measure of salience for the four globalisation-related issue domains based on the Politbarometer data for the period 1989-2020. In order to facilitate the interpretation of our relative salience measure, we also depict the most frequently mentioned issue domain, which is "Economic situation". Between 1994 and 2010, 40-60 \% of respondents considered a problem belonging to this domain to be one of the main problems in Germany. After 2010, its popularity declined: by the end of 2020 , only $11,4 \%$ of the Politbarometer respondents considered the "Economic situation" to be one of the two most important problems in Germany.

Figure 1A shows that until 2008 (2011) respondents almost never mentioned "Economic liberalism" ("Europe") compared to the most popular category "Economic situation". The sharp increase in the salience of "Economic liberalism" between 2008 and 2012 corresponds to the start of the international financial and banking crisis. In a similar vein, the problem category "Europe" experiences popularity peaks related to critical events only, such as the European sovereign debt crisis (the so-called "Euro-crisis") with the EU bailout of Greece, Spain and Italy between 2011 and 2014. As soon as these critical events lose significance, for instance because they have received a political response, the issue domains "Economic liberalism" and "Europe" lose their popularity entirely among Politbarometer respondents. In periods without any critical events, respondents barely mention problems belonging to these issue domains.

Turning now to Figure 1B, which compares the categories "Immigration" and "Environment" with "Economic situation", we can observe similar popularity peaks associated with critical events for the "Environment" category. For instance, the popularity peak in 2011 relates to the Japanese nuclear power plant disaster in Fukushima, while the popularity peak in 2000 relates to the implementation of eco taxes in Germany. Between 2017 and the middle of 2019, we observe a tremendous increase in the salience of "Environment", which relates to the emission value scandal in the German automative industry, the UN climate summit in Bonn, and especially the start of the mobilisation for the Fridays for Future movement. By the end of 2019, however, the environment issue domain loses in popularity. Yet, throughout 2020, its salience remains at a high and relatively constant level. As the Politbarometer data currently available only cover the period until the end of 2020, we cannot say how the recent and highly mediatised environmental disasters (e.g., Ahr valley flood 2021, the recurrent extreme droughts and heatwaves) have affected the salience of "Environment" issue.

Similarly, the issue domain "Immigration" has gained durable popularity in recent years. Also at the beginning of the 1990s, Politbarometer respondents mentioned "Immigration" relatively frequently as one of the most important problems in Germany. This period covers not only the reunification process and a series of serious attacks against asylum seekers in Germany but also the ethnic armed conflicts happening in former Yugoslavia, which resulted in a 
Figure 1: Share of mentions of the two most important problems in Germany, May 1989 - December 2020
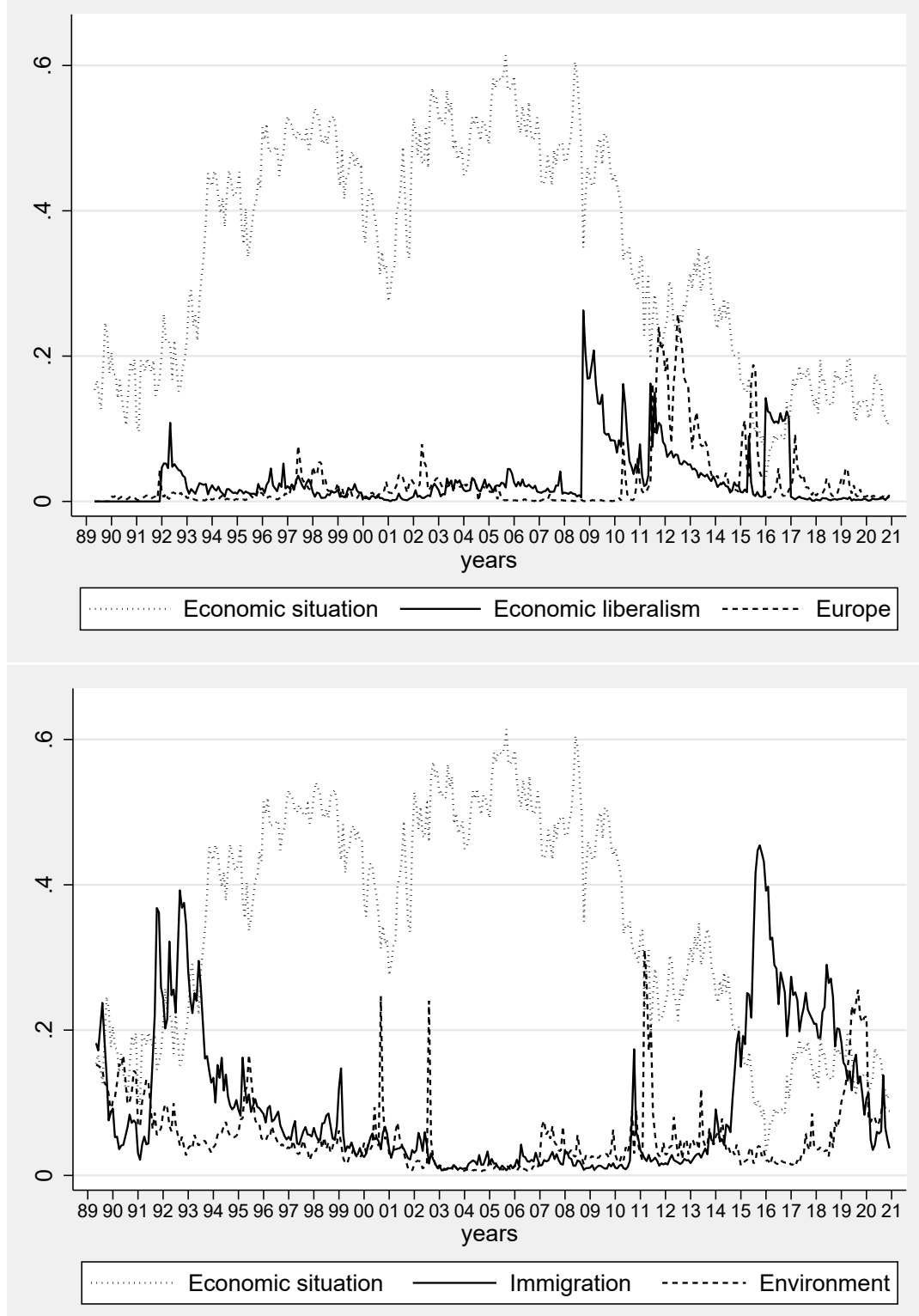

Notes: The Figure is based on the West German sample of the Politbarometer data until February 1999 and on its West and East German sample from March 1999 onwards. 
large number of asylum seekers from the Balkan region in Germany. ${ }^{3}$ Between the mid-1990s and 2015, the "Immigration" problem category lost its relative popularity with the exception of two short peaks in late 1998 and 2010. By contrast, in 2015, almost every second Politbarometer respondent mentions a problem belonging to the domain of "Immigration" as one of the two most important problems in Germany. This sudden gain in salience corresponds to the 2015 European "migrant crisis" (Eurostat, 2016). At that time, "Immigration" even overtrumped the category "Economic situation" in relative popularity and from 2015 to 2019, it constituted the most salient problem category. However, compared to its 2015 peak, the "Immigration" issue domain has lost popularity again. Nevertheless, respondents continue to frequently mention problems belonging to the domain of "Immigration".

All in all, based on our descriptive analysis of the Politbarometer trend data, we have observed an overall increase in salience for the issue of "Immigration" only since 2015, and for the issue of "Environment" only since 2017. Although the salience of both issues has declined again, "Immigration" and "Environment" still belong to the most popular problems mentioned by respondents until the end of the currently available Politbarometer Trend data. The loss in salience in 2020 is largely due to the rise in salience of another globalisationrelated issue: the Covid-19-pandemic that became the most salient issue in February 2020 until the end of the available Politbarometer trend data. As two of the four globalisation-related issue domains (i.e., economic liberalism and EU) experienced no durable increase in salience at all, we have to reject our first hypothesis at least in parts. Future waves will reveal whether "Immigration" and "Environment" gained durable salience or not.

\subsection{Opinion Polarisation}

We now go on and investigate our further hypotheses on opinion polarisation based on the ALLBUS data. Figure 2 presents the evolution of the opinion distribution of the selected ALLBUS items over time. The first two bar charts in Figure 2 refer to the items measuring trust in the European Commission and European identification, respectively. For both EU items, the size of the extreme category encompassing anti-EU attitudes decreased slightly from 2008. By contrast, the size of the other polar edge category constituted of pro-EU attitudes increased slightly during the same period. Thus, as not both polar edges grew in size over time, we cannot speak of an increasing polarisation of attitudes towards the EU among the German population since the 1990s.

Turning to the two bar charts on immigration in the row below, we observe that the size of the categories comprising the most positive attitudes towards immigration has largely increased over time. From 1996 to 2016, the proportion of respondents holding extremely positive attitudes toward immigration grew by 24,2 percentage points in the economic and 6,6 percentage points in the cultural

\footnotetext{
${ }^{3}$ Recall, however, that our analysis of the Politbarometer data excludes the population residing in East Germany until February 1999.
} 
Figure 2: Distribution of the globalisation-related items from the ALLBUS cumulative trend data

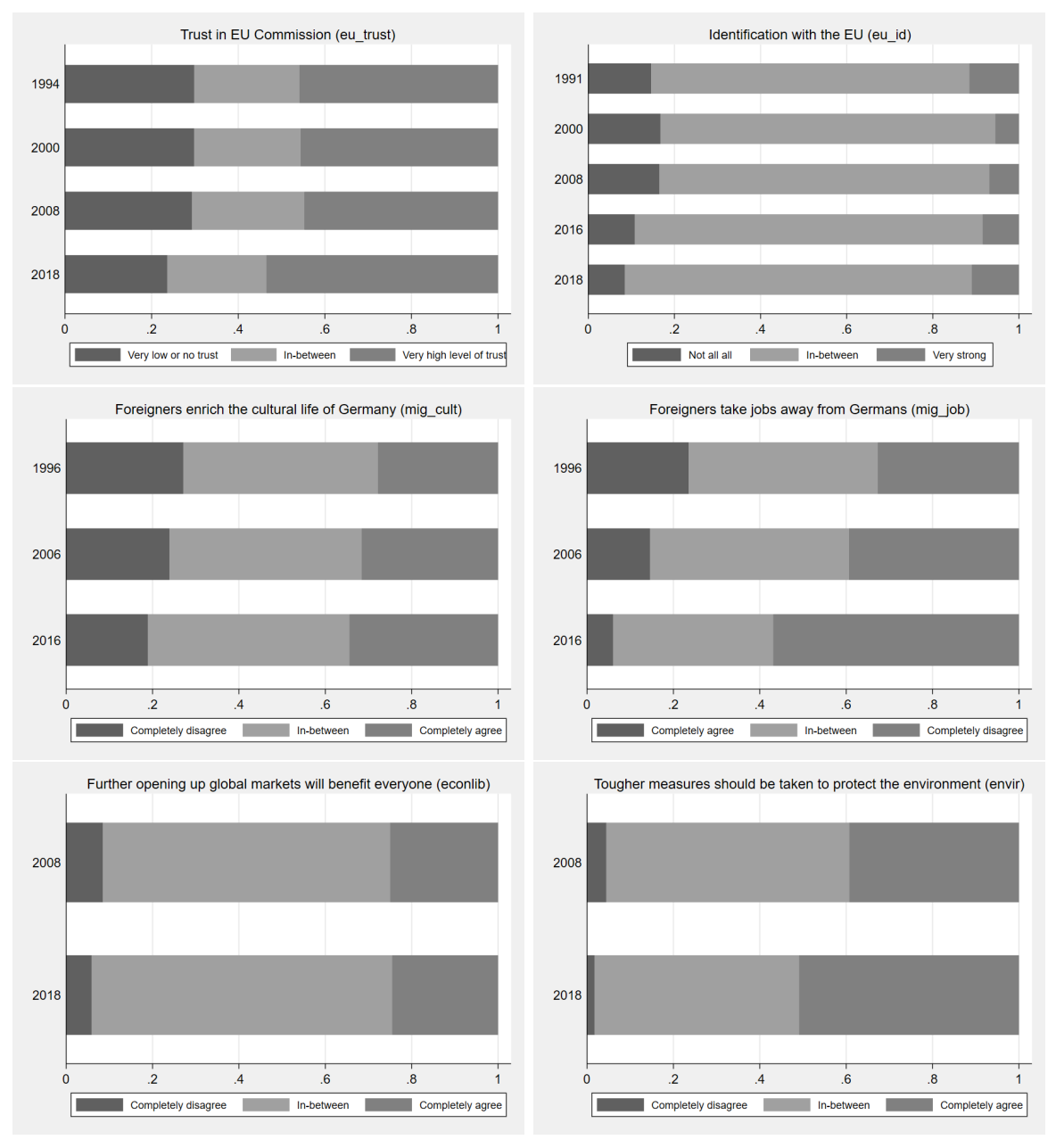


dimension. This goes hand in hand with a strong decrease in the proportion of citizens with extremely negative attitudes towards immigration. Moreover, the size of the middle-range opinion category remained stable over time. Thus, we observe an overall shift towards more pro-immigrant attitudes in both the cultural and economic dimensions since 1996, rather than an increase in opinion polarisation.

Lastly, the items referring to economic liberalism and environment protection were asked only in two ALLBUS waves, namely in 2008 and 2018. Unfortunately, this means that the assessment of opinion polarisation in respect of economic liberalism and environment protection suffers from severe limitations. The bar chart on the left in the last row of Figure 2 shows the distribution evolution of the item referring to economic liberalism, which points to stable opinions over time as the size of the two polar edges remains relatively similar. The bar chart on the right presents the evolution of the opinion distribution on environmental protection measures, showing a general shift towards the support of tougher measures. Here, both the middle category and the adverse polar category decrease in size. It is also noteworthy that in general only very few respondents show extremely negative attitudes towards environment protection measures $(4,4 \%$ in 2008 and $1,8 \%$ in 2018).

Overall, this first part of our investigation of overall opinion polarisation does not provide any support to our second hypothesis: we do not find simultaneous increases in both polar categories of the opinion distribution of any item related to globalisation. In the case of economic liberalism and the EU, attitudes appear relatively stable among the German population. Concerning immigration and environment protection, we detect general opinion shifts towards more supportive attitudes.

Turning to the second part of our analysis on opinion polarisation, Table 3 presents the agreement index of van der Eijk (2001) calculated for each item and each data wave. This calculation is now again based on the original number of answer categories (see Table 2). In order to confirm our hypothesis on opinion polarisation, the values on the agreement index for each item should get closer to -1 over time. However, the values either increase over time or remain stable (the latter is only the case for the EU trust item). Thus, these results point rather towards growing agreement than growing disagreement over time. This leads us to reject our second hypothesis: opinion polarisation on the issues of environment, economic liberalism, immigration and the EU has not increased over time among the German population.

Lastly, we investigate the extent to which group-level opinion polarisation increases over time. For this purpose, we estimate a linear regression model by OLS: each attitudinal globalisation-related item is regressed on survey year dummies, the socio-demographic characteristics mentioned in the Data section and the interaction terms between both (see Table 4). Each column corresponds to one of our six globalisation-related issues as the dependent variable. We use the first year in which the respective globalisation-related item was included in the ALLBUS data as the reference category in our regressions. If we were to observe an increase in group-level polarisation over time, the regression interaction 
Table 3: Van der Eijk's agreement index for the ALLBUS items on globalisationrelated issues

\begin{tabular}{lcccccccc}
\hline item & 1991 & 1994 & 1996 & 2000 & 2006 & 2008 & 2016 & 2018 \\
\hline eu_trust & 0,40 & & 0,41 & & 0,40 & & 0,42 \\
eu_id & 0,35 & & & 0,48 & & 0,43 & 0,43 & 0,42 \\
mig_cult & & & 0,07 & & 0,15 & & 0,18 & \\
mig_job & & 0,01 & & 0,15 & & 0,44 & \\
econlib & & & & 0,18 & & 0,30 \\
envir & & & 0,47 & 0,63 \\
\hline Notes: The agreement index ranges from -1 (complete disagreement or perfect \\
bimodality) to 1 (complete agreement or perfect unimodality). A value of 0 \\
denotes a uniform distribution.
\end{tabular}

terms between survey years and the socio-demographic characteristics would be significant and would go in the same direction as the main effect of the corresponding socio-demographic characteristic. This would indeed imply that the gap between the socio-demographic characteristic that serves as the reference category and the socio-demographic characteristic measured by the interaction term increases over time. Due to space constraints, we limit our interpretation to consistent trend patterns in order to evaluate our third hypothesis.

Turning to the first dependent variable (eu_trust: "trust in the EU Commission") presented in Table 4, group differences become significantly larger over time for the youngest cohort compared to the oldest cohort of respondents. Furthermore, differences between the groups of low educated and highly educated respondents increase significantly over time. Indeed, respondents with different educational levels do not differ significantly from each other on their level of trust in the EU Commission in 1994. By contrast, the group of highly educated respondents holds a significantly higher level of trust in the EU commission than the group of low educated respondents in 2008 and 2018. The remaining interaction terms are either insignificant or do not point to consistent trend patterns. If we now look at the second dependent variable (eu_id: "identification as European"), we see that educational differences and income differences systematically increase over time: respondents with a high educational level as well as those with a high income identify more and more strongly as European over time than do low educated respondents or those with a low income. By contrast, gender and age differences in identification as European significantly decrease over time. While males identified significantly stronger with the EU than females in $1991(+0.12$ points on a scale from 1 to 4$)$, this effect was close to zero in the following years (for example in 2000: $0.12-0.13=-0.01$ points). The other interaction terms are either insignificant or do not present any consistent trend. The third and fourth columns of Table 4 present the regression results on the two immigration-related attitudinal items (mig_cult and mig_job). The interaction terms with the survey years and the socio-demographic variables show similar patterns for both immigration items. First, we do not observe 
any consistent trend toward an increase in group differences in opinion on these immigration items. Second, age differences significantly decrease over time for both items. However, there is a trend pattern unique to mig_job ("foreigners take jobs from Germans"): differences between East and West Germans on this item decrease significantly over time (with East Germans having significantly more positive attitudes on this item over time).

Lastly, the interpretation of the results of the two remaining dependent variables is less straightforward: econlib and envir have been measured only twice so far. It is therefore dangerous to speak of any trend when observing significant differences in the regression coefficients between two measurement points. We only find a single interaction term for the regression results of both econlib and envir that suggests a significant increase in group differences between 2008 and 2018. Age differences between the youngest and oldest cohorts of respondents significantly increase in 2018 compared to 2008 in respect of the item "Opening world markets benefits everyone" (econlib): in 2018, respondents belonging to the youngest cohort disagree significantly more than respondents from the oldest cohort on this item. Several interaction terms for the two items econlib and envir point to a decrease in group differences over time, however. The opinion difference between educational groups on the item "Opening world markets benefits everyone" (econlib), which had been significant in 2008, came close to 0 by 2018. Furthermore, while East Germans hold significantly more positive attitudes toward the item "Tougher environmental measures should be taken" (envir) in 2008 at the $10 \%$ significance level, they show significantly more negative attitudes than West Germans on the same item ten years later. As both items were only measured at two points in time, we cannot draw any conclusion from these particular results.

All in all, we find very little support for our last hypothesis. We only find a consistent trend in increasing group differences for age on trust in the European Commission and on the item on international trade, as well as for educational levels on the items measuring trust in the European Commission and identification as European. The latter item also shows increasing group differences for income. Other socio-demographic differences in our six attitudinal globalisationrelated items either remain stable or even decrease over time.

We test the sensitivity of our results by including an additional control variable for migration status, operationalised by a dummy indicating being born in Germany. Overall, the results reported in Table 4 remain stable once we control for respondents' migration status. Moreover, we find the same patterns of significance and effect directions as shown in Table 4. In another set of sensitivity analyses, we use a categorized income variable in order to investigate the validity of our linear modeling of the relation of income on the dependent variables. With the exception of the "eu_trust" item, the association of the log of personal monthly net income with our dependent variables is linear. The online appendix contains the respective tables of our sensitivity analyses. 


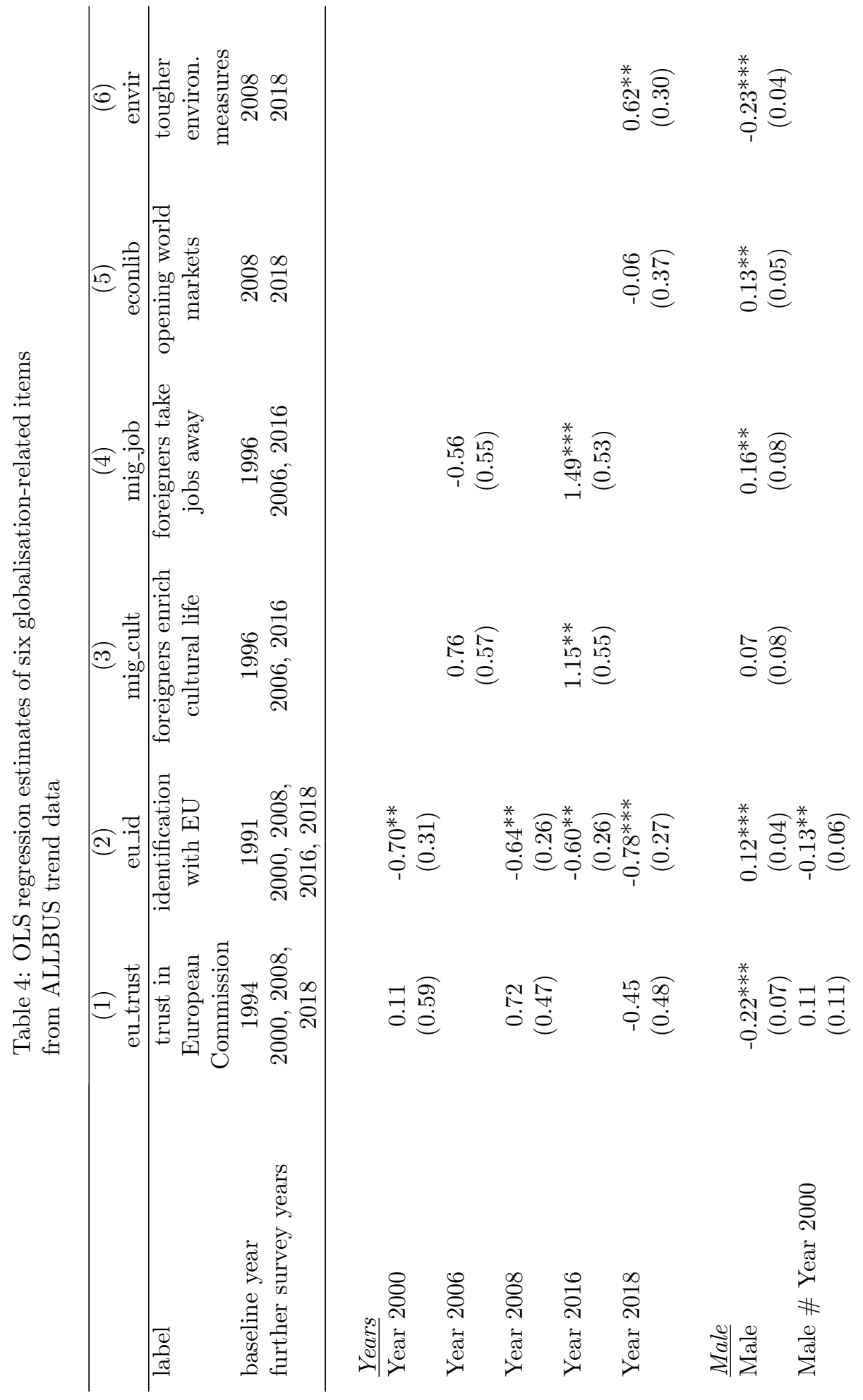




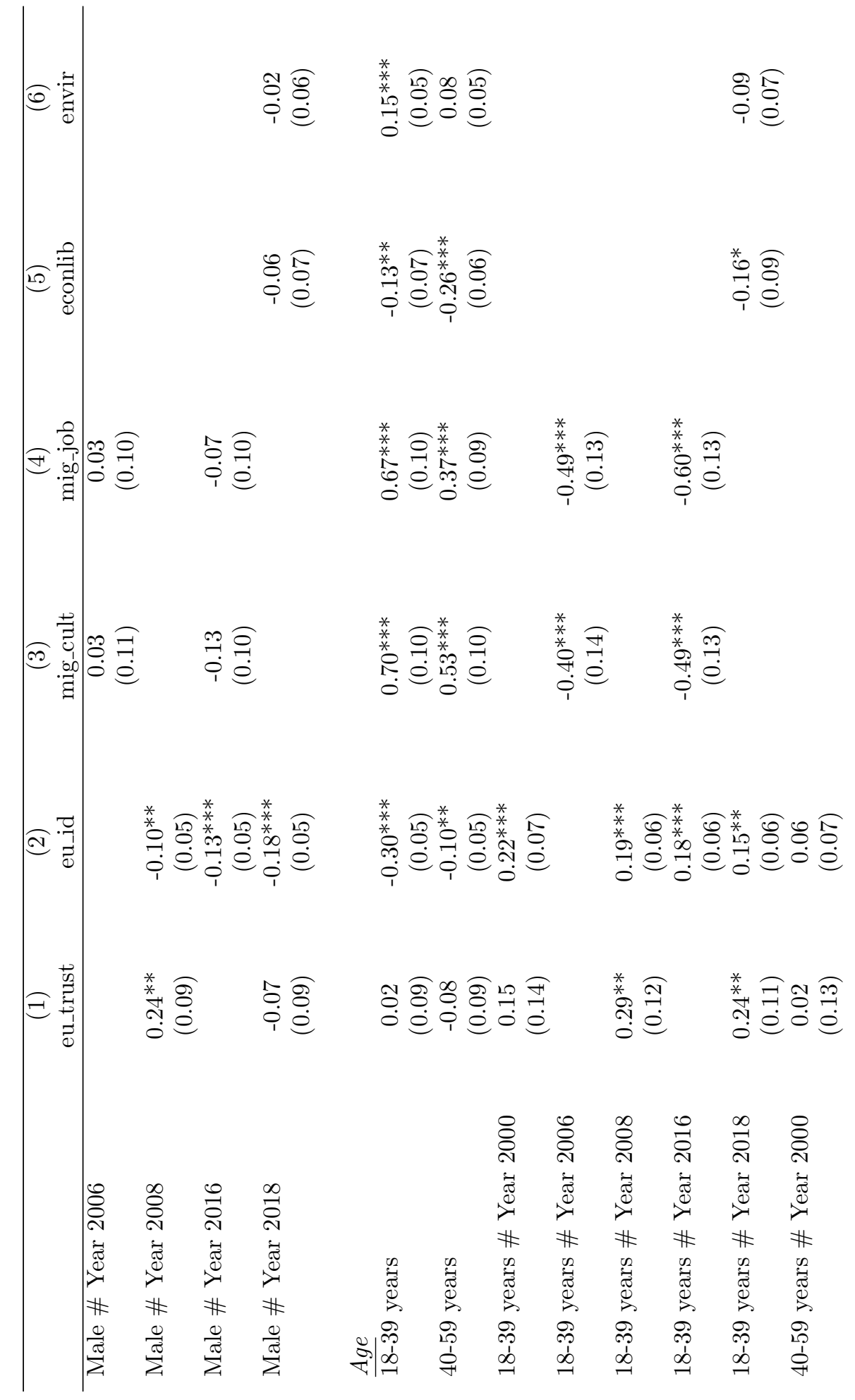




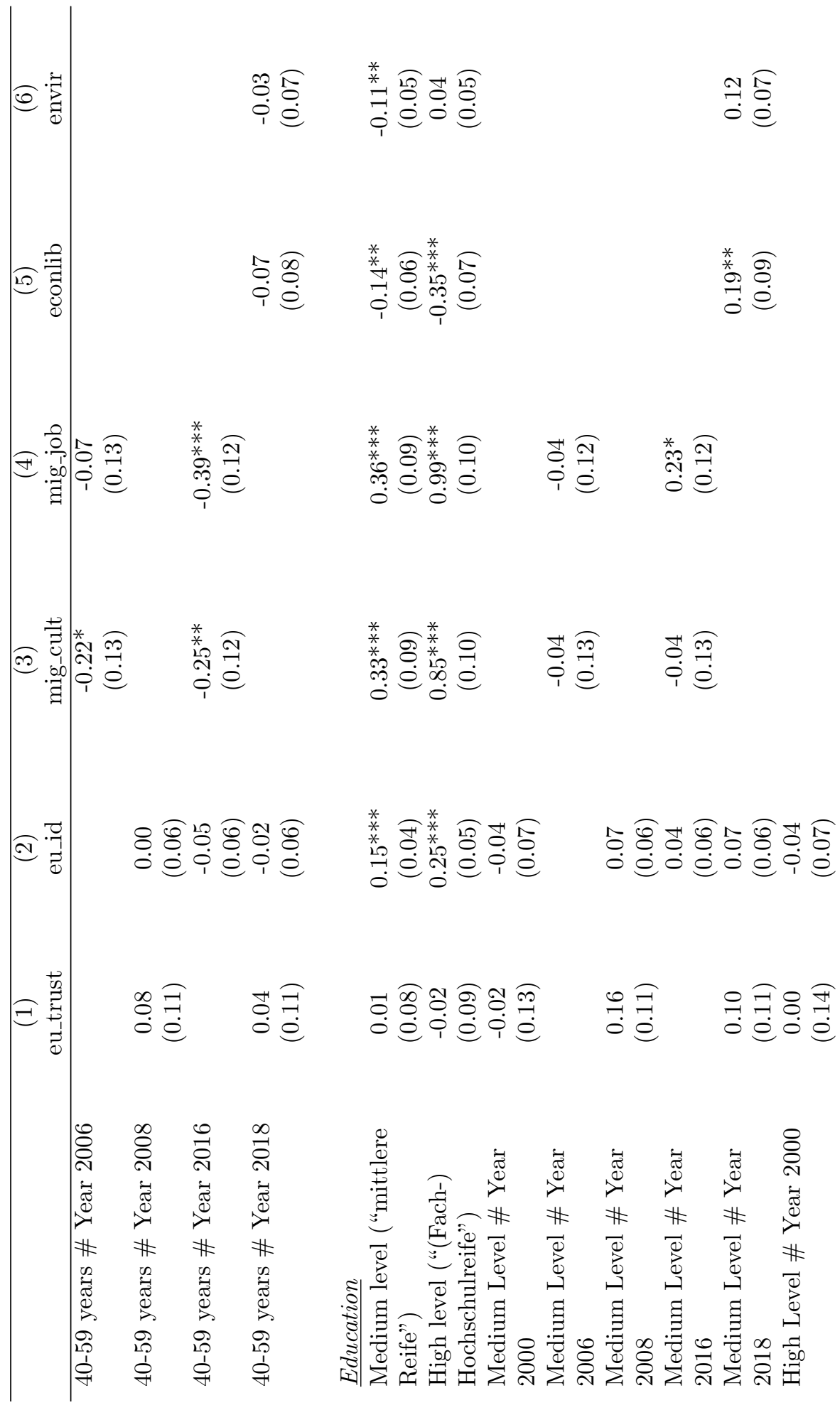




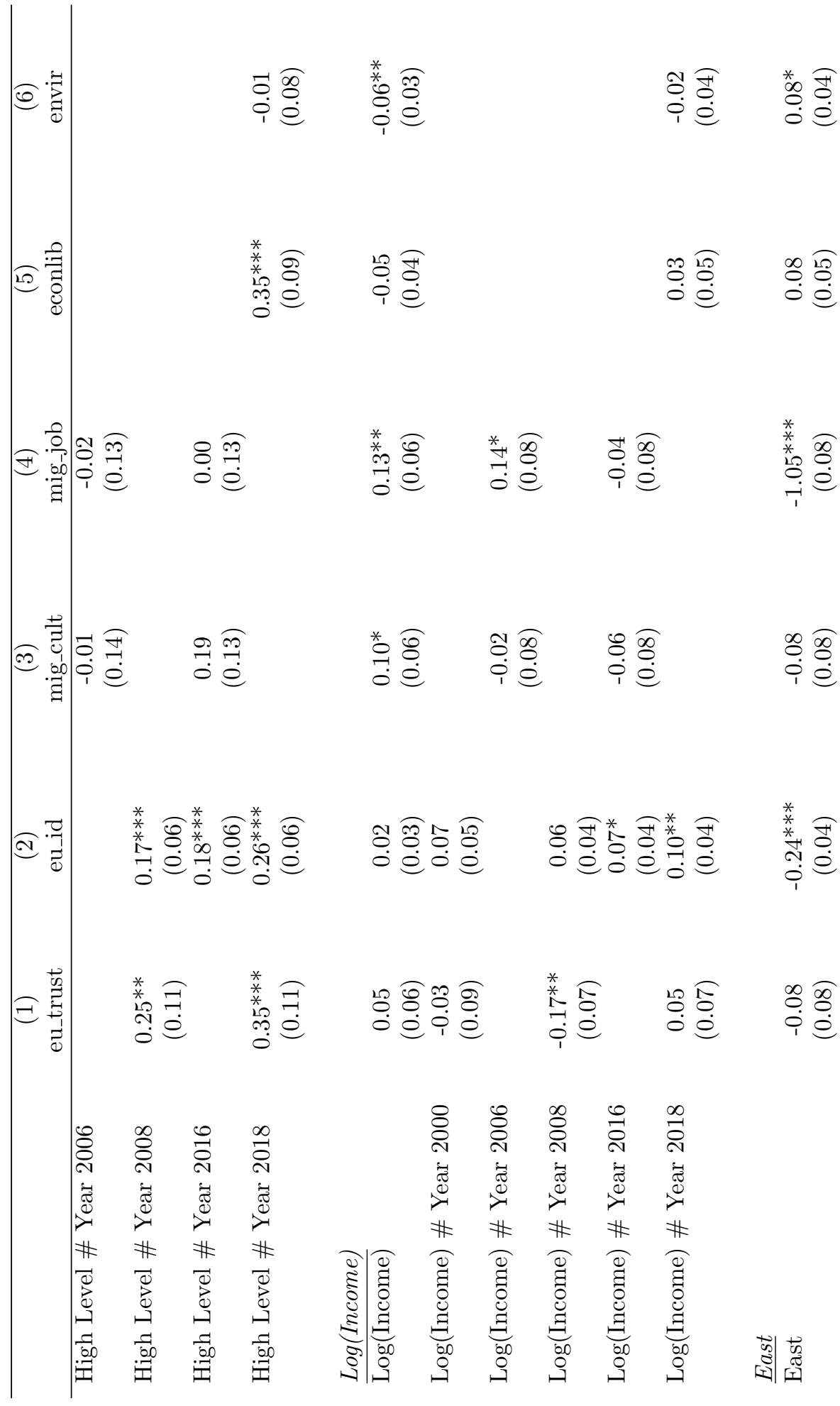




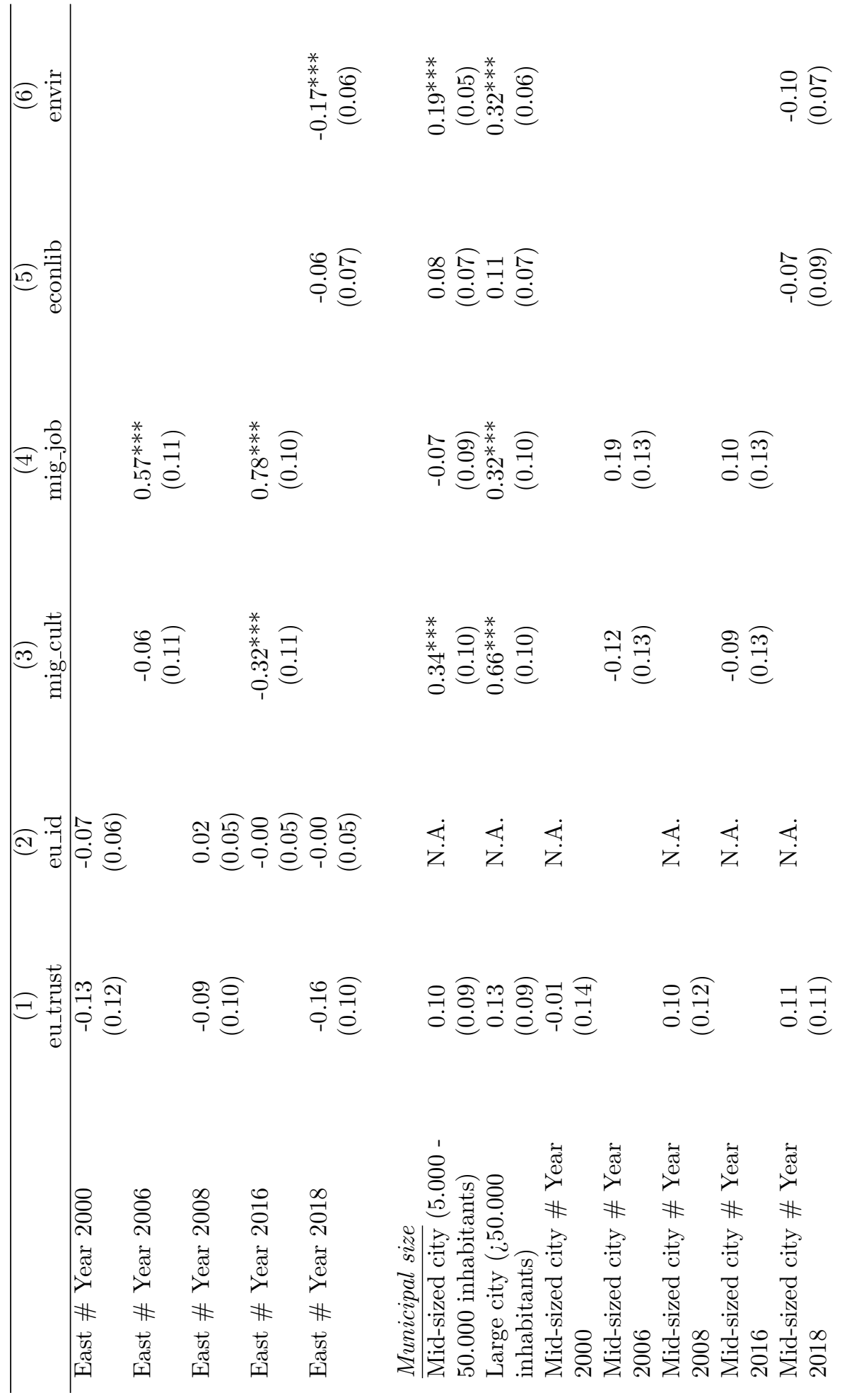




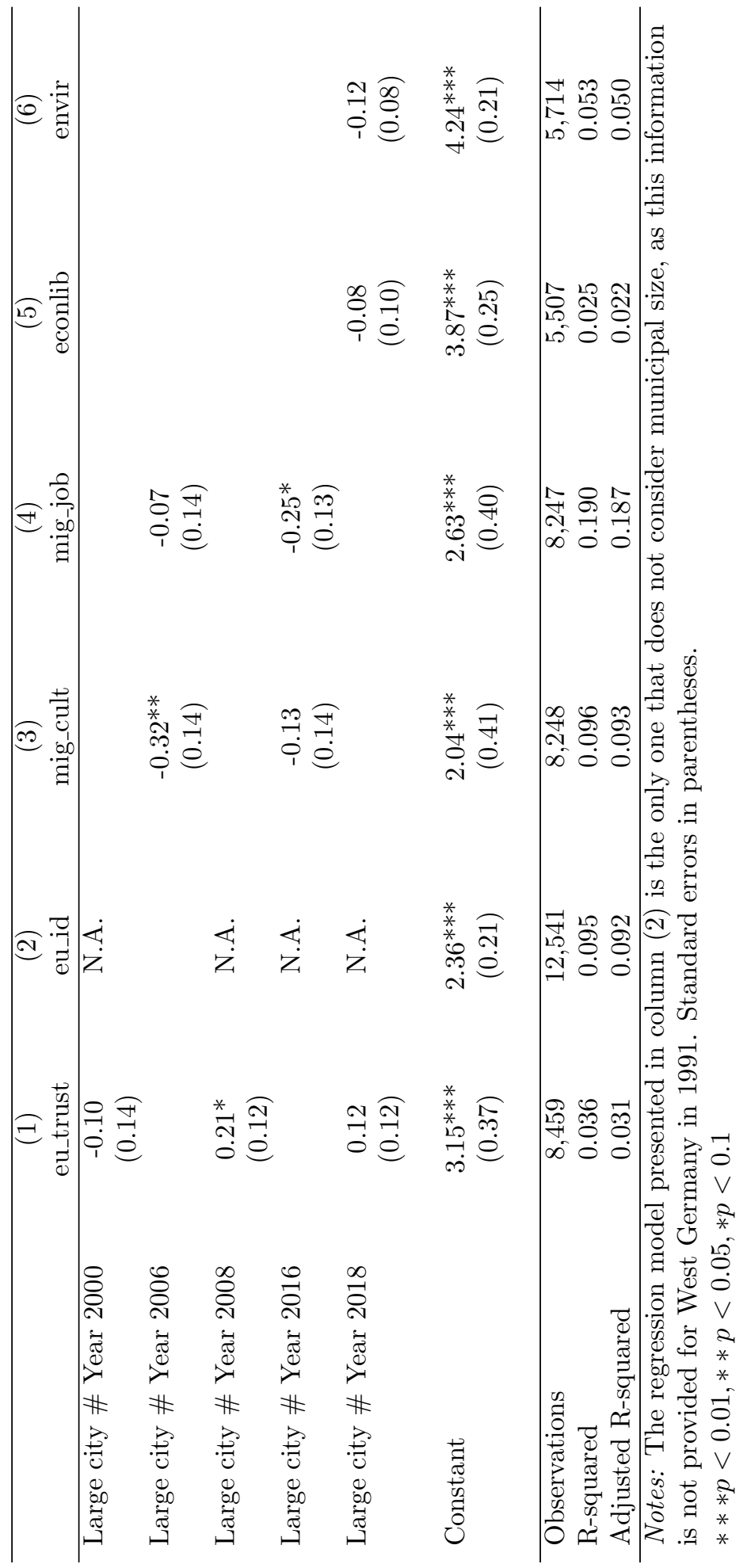




\section{Conclusion}

In this contribution, we investigate the extent to which the conditions for a new globalisation conflict among the German population are met. Drawing on cleavage theory, we stress the structuring force of social conflicts among the population, and highlight their integrative function. We argue that a social conflict on globalisation-related issues manifests through sustainable political mobilisation and that it requires two conditions: First, the population overall should consider globalisation-related issues as salient. Second, these globalisation-related issues should be contested within the population overall and between groups. We operationalise these two conditions as issue salience and overall and betweengroup opinion polarisation. Furthermore, we hypothesise that issue salience and overall and between-group opinion polarisation on globalisation-related issues should have increased over time as globalisation pressures have increased in the last decades in Europe (Gygli et al., 2019). We focus our analysis on the four globalisation-related issue domains of immigration, the EU, economic liberalism and the environment.

Our analysis of the salience of these issue domains among Germans from 1989 to 2020 points to an overall increase in salience for the issues of "Immigration" since 2015 and "Environment" since 2018. While both "Immigration" and "Environment" have recently been losing salience, they nevertheless still belong to the most popular problems mentioned by Germans until the end of the Politbarometer Trend data analysed. By contrast, the salience of the two other globalisation-related problems (i.e., "Economic liberalism" and "Europe") remains very low during the period 1989-2020 and exhibits short-duration peaks related to critical events only. This pattern reflects the results from studies on the politicisation of the EU in the media. Hutter et al. (2016, p. 283) conclude for example from their mass media content analysis that the politicisation of the EU shows "a process of punctuated politicisation, in which a significant but limited number of singular events produce high levels of political conflict for shorter periods of time". As only two of the four globalisation-related issue domains experienced an increase in salience, and this only very recently, our results can only partly confirm our first hypothesis on an overall increase in the salience of globalisation-related issues over time. Obviously, analyses based on the upcoming Politbarometer data waves will shed light on the sustainability of the popularity of "Immigration" and "Environment" as the most important problems among Germans. As our results clearly show, critical events have a great impact on issue salience among the German population. Recent and upcoming critical events, such as the COVID-19 pandemic or extreme weather events, are likely to relegate popular issues to second-order problems or push less popular issues to the rank of first-order problems among the population.

Turning now to overall opinion polarisation, our results indicate rather stable attitudes on globalisation-related issues among the German population over time. We only detect a general opinion shift towards more positive attitudes on immigration and environment protection measures. Thus, we cannot speak of an overall opinion polarisation on globalisation-related issues, if we understand 
opinion polarisation as a process whereby citizens position themselves increasingly on the two polar edges of an attitudinal divide (Barber and McCarty, 2015, p. 24). While our analysis shows that Germans hold antagonistic positions on some globalisation-related issues, this opinion divide has remained rather stable since the 1990s.

Lastly, our regression analyses of the main socio-demographic characteristics on six attitudinal globalisation-related items enabled us to investigate betweengroup polarisation over time. Here again, our results provide only very little support for the idea of an increasing between-group polarisation. Age differences in the level of trust in the European Commission and the level of support for international trade increase consistently and significantly over time. Moreover, highly educated Germans as well as Germans with a high income identify more and more strongly as Europeans over time than do Germans with low educational attainment or income. By contrast, the effects of all other sociodemographic differences yield a rather mixed picture without any consistent trend.

However, our analyses of overall and between-group opinion polarisation suffer from several weaknesses due to data limitations. First, some attitudinal items were characterised by a high number of missing cases for some ALLBUS waves (ranging from 0,28\% missing cases for the item mig_job in 1996 to 55 $\%$ missing cases for the item eu_trust in the year 2000). This, in turn, might alter the robustness of our findings on trends in polarisation. Second, some items used in our analyses constitute only poor measurements of opinion on globalisation-related issues - in particular the items on the EU and on environment protection. Third, the items on international trade and environment protection were only included in two ALLBUS survey waves. Lastly, the items analysed were not included in the same ALLBUS survey waves. This, in turn, hinders any meaningful between-items comparison of opinion polarisation over time. Moreover, we were not able to assess the extent to which citizens hold consistent opinions on distinct issues related to globalisation. In statistical terms, we were not able to compute correlation coefficients between the attitudinal items and investigate their evolution over time. Thus, while the Politbarometer Trend data provide a unique opportunity for investigating issue salience over time by virtue of their monthly data collection, general social survey trend data as provided by ALLBUS, for example, enable only an unsatisfactory assessment of opinion polarisation over time, at least with regard to globalisation as done here. It is therefore not feasible to draw any definitive conclusions on the evolution of opinion polarisation on globalisation among Germans on the basis of social survey trend data.

All in all, besides the recently increased popularity of "Immigration" and "Environment" as the most important problems among Germans, we find very little empirical support for the idea of an emerging conflict around globalisationrelated issues among the German population. Our results come as a surprise when we consider a common interpretation that receive a great deal of attention in the public debate, such as the rise of a globalisation backlash or a conflict between winners and losers of globalisation in Germany. Such an interpretation 
tends to be drawn without a longitudinal perspective. As we have shown, the population does hold antagonist positions on some globalisation-related issues, but this opinion divide has remained constant over time. Moreover, such an interpretation often fails to consider the salience given by the population to such issues. Hence, our study points to the importance of fine-grained and sound descriptive analyses of such a highly mediatised interpretation. This helps contextualise and relativise the somewhat alarmist conclusions attracting a great deal of resonance in the public debate (see Mau et al. 2020 for a similar argument).

Furthermore, our study provides results which contradict the current social sciences debate on the rise of a globalisation cleavage. Indeed, our results highlight the lack of a structural component in Germany, which would be necessary to be able to speak of a globalisation cleavage as defined by Bartolini and Mair (1990). Thus, the current politicisation and mobilisation around globalisationrelated issues in Germany seem to be driven by the supply rather than by the demand side of the political system. These results are in line with one argument of Walter (2021): the electoral success of political actors with an antiglobalisation programme is the result of an increasing mobilisation of existing anti-globalisation attitudes rather than the result of a shift in public opinion towards globalisation-related issues. Indeed, political entrepreneurs offering a political platform for citizens holding anti-globalisation attitudes have flourished in the last decade (Bornschier, 2018). By trying to mobilise voters on these issues, they have increased the visibility of globalisation-related issues in the public debate (Walter, 2021). The politicisation of particular issues driven by political parties has been shown, in turn, to be associated with greater opinion polarisation among the population on the corresponding issue (Ares, 2022). Thus, the political context largely matters in shaping the structural component of a cleavage. In-depth studies on the interaction between the politicisation of public debate and opinion polarisation on globalisation-related issues would help us to better understand the interdependency between all three components of a cleavage.

Furthermore, our results highlight the need for more in-depth empirical studies focusing on the demand side of this assumed globalisation cleavage. Indeed, investigating the extent to which our results can be transposed to other (Western) EU countries would make an important contribution to the academic debate on the rise of a globalisation cleavage. Additionally, fine-grained analyses of trends in opinion polarisation along other key socio-demographic characteristics are essential for a better assessment of a potential rise of social conflicts due to globalisation pressures (see for instance Dochow-Sondershaus \& Teney, 2022, for opinion polarisation along occupational classes). Another important and complementary research avenue concerns the role of the media in (the perception of) a conflict on globalisation-related issues. Indeed, both traditional media (Czymara and Dochow, 2018) and social media (Bail et al., 2018) have been shown to play an important role in shaping attitudes towards globalisationrelated issues as well as for their perceived salience. Considering traditional and social media as binding links between the supply and demand sides might help 
understand the mismatch between the popular perception of a growing opinion polarisation on globalisation-related issues and our contradictory findings. 


\section{References}

Ares, M. (2022). Issue politicization and social class: How the electoral supply activates class divides in political preferences. European Journal of Political Research, 61(2):503-523.

Bail, C. A., Argyle, L. P., Brown, T. W., Bumpus, J. P., Chen, H., Hunzaker, M. B. F., Lee, J., Mann, M., Merhout, F., and Volfovsky, A. (2018). Exposure to opposing views on social media can increase political polarization. Proceedings of the National Academy of Sciences, 115(37):9216-9221.

Barber, M. J. and McCarty, N. (2015). Causes and Consequences of Polarization. In Persily, N., editor, Solutions to Political Polarization in America, pages 15-58. Cambridge University Press.

Bartolini, S. (2000). The Political Mobilization of the European Left, 1860-1980: The Class Cleavage. Cambridge University Press.

Bartolini, S. and Mair, P. (1990). Identity, Competition and Electoral Availability: The Stabilisation of European Electorates 1885-1985. Cambridge University Press.

Bonacker, T., editor (2003). Sozialwissenschaftliche Konflikttheorien: Eine Einführung. Friedens- und Konfliktforschung. VS Verlag für Sozialwissenschaften, Wiesbaden, second edition.

Bornschier, S. (2018). Globalization, Cleavages, and the Radical Right. In Rydgren, J., editor, The Oxford Handbook of the Radical Right, pages 212-238. Oxford University Press.

Bornschier, S., Häusermann, S., Zollinger, D., and Colombo, C. (2021). How "Us" and "Them" Relates to Voting Behavior-Social Structure, Social Identities, and Electoral Choice. Comparative Political Studies, 54(12):2087-2122.

Claassen, C. and McLaren, L. M. (2022). Does Immigration Produce a Public Backlash or Public Acceptance? Time-Series, Cross-Sectional Evidence from 27 European Democracies. British Journal of Political Science, 52(3):1013-1031.

Coser, L. (1956). The Function of Social Conflict. Routledge \& K. Paul.

Czymara, C. S. and Dochow, S. (2018). Mass Media and Concerns about Immigration in Germany in the 21st Century: Individual-Level Evidence over 15 Years. European Sociological Review, 34(4):381-401.

Dahrendorf, R. (1971). Zu einer Theorie des sozialen Konflikts. In Zapf, W., editor, Theorien Des Sozialen Wandels, pages 108-123. Kiepenheuer \& Witsch.

De Vries, C. E. (2018). Euroscepticism and the Future of European Integration. Oxford University Press. 
De Vries, C. E., Hobolt, S. B., and Walter, S. (2021). Politicizing International Cooperation: The Mass Public, Political Entrepreneurs, and Political Opportunity Structures. International Organization, 75(2):306-332.

Dennison, J. (2019). How Issue Salience Explains the Rise of the Populist Right in Western Europe. International Journal of Public Opinion Research, $32(3): 397-420$.

Dennison, J. and Geddes, A. (2019). A Rising Tide? The Salience of Immigration and the Rise of Anti-Immigration Political Parties in Western Europe. The Political Quarterly, 90(1):107-116.

DiMaggio, P., Evans, J., and Bryson, B. (1996). Have American's Social Attitudes Become More Polarized? American Journal of Sociology, 102(3):690-755.

Dochow-Sondershaus, S. and Teney, C. (2022). Trends in structural polarization in attitudes towards immigration and the European Union in Germany: The role of occupational classes. Preprint, SocArXiv.

Druckman, J. N. and Levendusky, M. S. (2019). What Do We Measure When We Measure Affective Polarization? Public Opinion Quarterly, 83(1):114-122.

Forschungsgruppe Wahlen, Mannheim (2022). Partial Cumulation of Politbarometers 1977-2020. GESIS Data Archive, Cologne. ZA2391 Data file Version 13.0.0, https://doi.org/10.4232/1.13837. Technical report, Cologne.

GESIS - Leibniz Institute for the Social Sciences (2021). Cumulated German General Social Survey GGSS 1980-2018, ZA5274 data file version 1.1.0. Technical report, Cologne.

Gygli, S., Haelg, F., Potrafke, N., and Sturm, J.-E. (2019). The KOF Globalisation Index - Revisited. The Review of International Organizations, 14(3):543574 .

Hetherington, M. J. (2009). Putting Polarization in Perspective. British Journal of Political Science, 39(2):413-448.

Hooghe, L. and Marks, G. (2018). Cleavage theory meets Europe's crises: Lipset, Rokkan, and the transnational cleavage. Journal of European Public Policy, 25(1):109-135.

Hutter, S., Grande, E., and Kriesi, H. (2016). Politicising Europe: Mass Politics and Integration. Cambridge University Press.

Hutter, S. and Kriesi, H. (2019). European Party Politics in Times of Crisis. Cambridge University Press.

Jennings, W. and Stoker, G. (2016). The Bifurcation of Politics: Two Englands. The Political Quarterly, 87(3):372-382. 
Jungherr, A., Mader, M., Schoen, H., and Wuttke, A. (2018). Context-driven attitude formation: The difference between supporting free trade in the abstract and supporting specific trade agreements. Review of International Political Economy, 25(2):215-242.

Kriesi, H., Grande, E., Lachat, R., Dolezal, M., Bornschier, S., and Frey, T. (2008). West European Politics in the Age of Globalization. Cambridge University Press.

Kuhn, T., van Elsas, E., Hakhverdian, A., and van der Brug, W. (2016). An ever wider gap in an ever closer union: Rising inequalities and euroscepticism in 12 West European democracies, 1975-2009. Socio-Economic Review, 14(1):27-45.

Lipset, S. M. and Rokkan, S. (1967). Party Systems and Voter Alignments. Cross-national Perspectives. The Free Press.

Mau, S., Lux, T., and Gülzau, F. (2020). Die drei Arenen der neuen Ungleichheitskonflikte. Eine sozialstrukturelle Positionsbestimmung der Einstellungen zu Umverteilung, Migration und sexueller Diversität. Berliner Journal Fur Soziologie, 30(3-4):317-346.

McCright, A. M., Dunlap, R. E., and Marquart-Pyatt, S. T. (2016). Political ideology and views about climate change in the European Union. Environmental Politics, 25(2):338-358.

Meunier, S. and Czesana, R. (2019). From back rooms to the street? A research agenda for explaining variation in the public salience of trade policy-making in Europe. Journal of European Public Policy, 26(12):1847-1865.

Munzert, S. and Bauer, P. C. (2013). Political Depolarization in German Public Opinion, 1980-2010. Political Science Research and Methods, 1(1):67-89.

Rauh, C. (2015). Communicating supranational governance? The salience of EU affairs in the German Bundestag, 1991-2013. European Union Politics, 16(1):116-138.

Simmel, G. (1992). Der Streit. In Soziologie. Untersuchungen Über Die Form Der Vergesellschaftung, pages 284-382. Suhrkamp Taschenbuch Wissenschaft.

Teney, C. (2016). Does the EU economic crisis undermine subjective Europeanization? Assessing the dynamics of citizens' EU framing between 2004 and 2013. European Sociological Review, 32(5):619-633.

Teney, C., Lacewell, O. P., and de Wilde, P. (2014). Winners and losers of globalization in Europe: Attitudes and ideologies. European Political Science Review, 6(4):575-596.

van der Eijk, C. (2001). Measuring Agreement in Ordered Rating Scales. Quality and Quantity, 35(3):325-341. 
Walter, S. (2021). The Backlash Against Globalization. Annual Review of Political Science, 24(1):421-442.

Wlezien, C. (2005). On the salience of political issues: The problem with 'most important problem'. Electoral Studies, 24(4):555-579. 


\section{Appendix A}

Table A.1: Variance of the ALLBUS items on globalisation-realted issues

\begin{tabular}{lllllllll}
\hline item & 1991 & 1994 & 1996 & 2000 & 2006 & 2008 & 2016 & 2018 \\
\hline eu_trust & & 2,06 & & 1,97 & & 2,04 & & 1,95 \\
eu_id & 0,79 & & & 0,62 & & 0,67 & 0,63 & 0,64 \\
mig_cult & & & 3,77 & & 3,38 & & 3,36 & \\
mig_job & & & 4,15 & & 3,53 & & 2,58 & \\
econlib & & & & & & 1,68 & & 1,45 \\
envir & & & & & & 1,30 & & 0,91 \\
\hline
\end{tabular}

Table A.2: Skewness of the ALLBUS items on globalisation-realted issues

\begin{tabular}{lllllllll}
\hline item & 1991 & 1994 & 1996 & 2000 & 2006 & 2008 & 2016 & 2018 \\
\hline eu_trust & & 0,10 & & $-0,02$ & & 0,11 & & $-0,13$ \\
eu_id & 0,18 & & & 0,33 & & 0,14 & 0,03 & $-0,02$ \\
mig_cult & & & 0,02 & & $-0,15$ & & $-0,24$ & \\
mig_job & & & $-0,08$ & & $-0,33$ & & $-0,90$ & \\
econlib & & & & & & $-0,28$ & & $-0,43$ \\
envir & & & & & & $-1,00$ & & $-1,42$ \\
\hline
\end{tabular}

Table A.3: Kurtosis of the ALLBUS items on globalisation-related issues

\begin{tabular}{lllllllll}
\hline item & 1991 & 1994 & 1996 & 2000 & 2006 & 2008 & 2016 & 2018 \\
\hline eu_trust & & 2,54 & & 2,33 & & 2,52 & & 2,44 \\
eu_id & 2,29 & & & 2,74 & & 2,45 & 2,54 & 2,54 \\
mig_cult & & & 1,92 & & 2,07 & & 3,12 & \\
mig_job & & & 1,79 & & 2,07 & & 2,10 & \\
econlib & & & & & & 1,88 & & 2,15 \\
envir & & & & & & 3,14 & & 4,63 \\
\hline
\end{tabular}


Table A.4: Summary statistics of ALLBUS variables

\begin{tabular}{|c|c|c|c|c|c|c|}
\hline & & mean & sd & $\min$ & $\max$ & $\mathrm{N} / \%$ \\
\hline \multicolumn{7}{|c|}{ dependent variables } \\
\hline eu_trust & trust in European Commission & 3,41 & 1,42 & 1 & 7 & 10.322 \\
\hline eu_id & identification with EU & 2,36 & 0,83 & 1 & 4 & 15.059 \\
\hline econlib & opening world markets & 3,45 & 1,25 & 1 & 5 & 6.608 \\
\hline envir & tougher environmental measures & 4,10 & 1,06 & 1 & 5 & 6.863 \\
\hline mig_job & foreigners take jobs away & 4,66 & 1,92 & 1 & 7 & 10.345 \\
\hline mig_cult & foreigners enrich cultural life & 4,10 & 1,88 & 1 & 7 & 10.340 \\
\hline \multicolumn{7}{|c|}{ independent variables } \\
\hline male & & 0,49 & 0,50 & 0 & 1 & 50.013 \\
\hline east & & 0,33 & 0,47 & 0 & 1 & 50.013 \\
\hline linc & $\log$ of income & 6,94 & 0,73 & 0 & 11 & 40.312 \\
\hline \multirow[t]{4}{*}{ age } & age in categories & & & 1 & 3 & 49.939 \\
\hline & 1: $18-39$ years old & & & & & $34,80 \%$ \\
\hline & 2: 40-59 years old & & & & & $36,22 \%$ \\
\hline & 3: 60 years and older & & & & & $28,98 \%$ \\
\hline \multirow[t]{4}{*}{ educ } & educational attainment in categories & & & 1 & 3 & 49.639 \\
\hline & 1: low & & & & & $40,34 \%$ \\
\hline & 2: middle & & & & & $32,63 \%$ \\
\hline & 3: high & & & & & $27,03 \%$ \\
\hline \multirow[t]{4}{*}{ munsize } & municipal size in categories & & & 1 & 3 & 48.374 \\
\hline & 1: under 5.000 inhabitants & & & & & $21,43 \%$ \\
\hline & 2: 5.000 to 50.000 inhabitants & & & & & $41,79 \%$ \\
\hline & 3: over 50.000 inhabitants & & & & & $36,78 \%$ \\
\hline
\end{tabular}

Notes: We recoded educational attainment in three categories: "low" refers to no school leaving certificate or elementary school certificate ("Volks- or Hauptschulabschluss"), "middle" refers to intermediary secondary qualifications ("Mittlere Reife"), "high" refers to school leaving certificates qualifying for studies at the university level ("Fach- und Hochschulreife").

\section{Appendix B}

The computation of the measure of agreement A (van der Eijk, 2001) can be summarised as follows:

- Firstly, decompose the empirical distribution into layers. Each layer consists of the same number of categories as the original distribution, and each category consists of either zero cases or exactly as many cases as the other categories. Therefore, these layers can also be described as semi-uniform components of the original distribution. They are then represented by binary terms, where 0s represent empty categories and 1s represent nonempty ones. Please refer to van der Eijk (2001) for a graphical represen- 
tation. An index $i=1, \ldots, K$ makes it possible to differentiate between the various layers.

- Calculate the measure of unimodality $U_{i}$ for any layer $i$ containing both 0 s and 1s:

$$
U_{i}=\frac{(K-2) \times T U-(K-1) \times T D U}{(K-2) \times(T U+T D U)},
$$

where $K$ is the total number of categories in the rating scale, $T U$ the number of triples of categories conforming to unimodality, and $T D U$ the number of triples of categories deviating from a unimodal pattern. If layer $i$ consists of 1 s only, then $T U=T D U=0$ and $U_{i}=1$.

- Agreement in layer i is measured as follows:

$$
A_{i}=U_{i} \times\left(1-\frac{(S-1)}{(K-1)}\right),
$$

where $S$ is the number of non-empty categories in this layer, and $K$ is the total number of categories in the rating scale.

- Finally, the layer-specific agreement measures are added up as follows:

$$
A=\sum_{i} A_{i} \times w_{i}
$$

where $w_{i}$ is layer i's share of observations, serving as a weight. 